\title{
Delicate Situation of Bipolar Disorder and Interferon Therapy
}

Sir,

The comorbidity associating a bipolar disorder and a hepatitis $\mathrm{C}$ rise a great issue of therapeutic care. While the interferon is very known to destabilize the mood, practitioners evoke the possibility of administrating antiviral treatment for patients suffering of mood disorder. Hence, we report a 54-year-old patient suffering from a bipolar disorder type I. The patient has rich familial history of bipolar disorder. We discuss the clinical and therapeutical features raised by the combination of both: bipolar disorder and interferon alpha therapies.

Our patient has consented according to national regulations, He was 54-year-old and suffering of a bipolar disorder type I. The patient is married and father of 3 children, he is inspector of high school and has rich familial history of bipolar disorder: His father, three brothers, and two cousins are affected by a mood disorders, indeed a cousin committed a suicide while suffering from a major depressive disorder.

The bipolar disorder started while our patient was 18-year-old, this was expressed by a major episode of depressive disorder lasting 4 months. Two years later, the patient presented manic episode. The evolution was marked by several depressive or manic episodes, occurring every 2 years in average. Between consecutive episodes, the patient regained all his social and professional activities. The patient presented only depressive episodes since being 45 years old. He was treated using thymoregulators, the last one used was Carbamazepine at $800 \mathrm{mg}$ /day. A viral hepatitis $\mathrm{C}$ of genotype $1 \mathrm{~b}$ was diagnosed in 2002; this was achieved while investigating asthenia, diabetes of type I was also revealed in the same context. A hepatic biopsy was conducted in 2008 and found severe fibrosis of score Fibrotest F3, without cirrhosis state.

The antiviral treatment was delayed for 3 months considering the association of simultaneous depressive episode. After mood disorder stabilization (score BDI at 4), the antiviral treatment was started using pegylated interferon alpha $2 \mathrm{a}$ at $180 \mu \mathrm{g} /$ week and Ribavirin at $1200 \mathrm{mg}$ /day. A preventive psychiatric treatment was added and consisted of thymoregulator and antidepressant, respectively, carbamazepine $800 \mathrm{mg} /$ day and tianeptine $75 \mathrm{mg} /$ day.

Two weeks after starting the antiviral treatment, the patient showed minor mood symptoms, without categorized depression. Four weeks later, the depressive symptoms became more marked; the patient reported an important depression, anhedonia, feelings of dissuasion, culpability, associating major anxiety symptoms with BDI score of 16, and Hamilton score of Anxiety scale of 17.

Two weeks later, depressive symptoms were increased especially after the $8^{\text {th }}$ week. Intense moral pain and suicidal ideation were recorded. An attempt suicide was executed using insulin injection and ingestion of psychotropic drugs tablets. Emergency hospitalization was required in the Intensive Care Unit. After stabilization of intoxication symptoms, the decision of the stopping the antiviral interferon therapy was adopted by consent of psychiatrists and hepatologist in the $9^{\text {th }}$ week of the antiviral treatment. The evolution was marked by a clear improvement of the depressive symptoms. Psychiatrists and hepatologists concluded that 
the major depressive disorder is most probably related to the interferon therapy. Consequently, after 18 months of mood stabilization (BDI in 3), and considering mood disorder episodes occurring every 2 years, the medical staff decided to delay the antiviral treatment to avoid recurrent mood episodes and the suicidal risk.

Clinical experiences and studies showed that the antiviral treatment of the HVC might induce mood disorders in bipolar patients; this generally occurs throughout the treatment or during the 6 months following a stopping the antiviral treatment. ${ }^{[1]}$ Depressive disorders are the most frequent and the most severe psychiatric manifestations. The last prospective study found a prevalence of $26 \%$ of depressive disorders at 24 weeks of antiviral treatment. ${ }^{[2]}$

These disorders would be more important while a previous psychiatric disorders history is found such results were found in our reported case. Bipolar patients are more predisposed to mood episodes induced by the antiviral treatment. ${ }^{[3]}$ The prevalence of suicide attempts is estimated at $1.5 \%$ during the antiviral treatment. ${ }^{[4]}$ Rifflet et al. reported a prevalence of $1.3 \%$ in the 6 months following the stopping of the antiviral treatment. ${ }^{[2]}$ Hence, excluding the treatment, these patients by the interferon alpha are not still justified. Revealed mood disorders can be managed, once they are diagnosed and treated early in an adequate way. In addition, several reported cases with hepatitis $\mathrm{C}$ and bipolar disorders could achieve their interferon alpha cures without significant degradation of their psychiatric state. ${ }^{[1]}$

The prescription of antidepressants medication in the depressive episode induced by the interferon is generally proved by extensive studies. However, the prophylactic antidepressant treatment remains to be proved. Three studies found inconsistent results. For example, Schaefer et al. ${ }^{[5]}$ demonstrated that the administration of citalopram is associated to a reduction of the incidence of depression induced by the interferon. In contrast, Morasco et al. and Raison et al..$^{[4,6]}$ did not find any significant difference of incidence of depression induced while studying placebo and paroxetine groups. Our case has well showed a depressive episode with melancholic features despite the administration of thymoregulator and antidepressant, and the BDI score was 4 before the beginning of the antiviral treatment. It is still to justify the prophylactic prescription of antidepressant in bipolar patient showing only depressive episodes such our case.

Recently, Kelly et al. concluded from retrospective study of 16 bipolar stable patients that they could benefit of interferon-alpha therapy with successful outcome with the same success range compared to patients without depression history. ${ }^{[7]}$ However, this conclusion is too early since it was drawn from very limited sample of patients without taking into account the severity and the duration of the bipolar disorder. Hence, we rise the following issues: Is the concern of mood inversion raised? And what is the minimal duration of mood stabilization required for restarting the antiviral treatment? There is not a consensus on the protocol of management of such cases. A mixed team of psychiatrists and hepatologists concluded the interest of a long period of mood stabilization associating hepathological follow-up.

The interferon alpha therapy is a critical treatment whenever required for hepatitis $\mathrm{C}$ patients. However, whenever they present a history of bipolar disorder, it is also essential to consider the severity and history of the mood disorder whenever administrating interferon treatment; this would allow to avoid aggravating the depression symptoms, hence, threatening the life of the patient by possible suicidal initiative.

\section{Declaration of patient consent}

The authors certify that they have obtained all appropriate patient consent forms. In the form the patient(s) has/have given his/her/their consent for his/ her/their images and other clinical information to be reported in the journal. The patients understand that their names and initials will not be published and due efforts will be made to conceal their identity, but anonymity cannot be guaranteed.

\section{Financial support and sponsorship}

Nil.

\section{Conflicts of interest}

There are no conflicts of interest.

Chadya Aarab ${ }^{1,2}$, Rachid Aalouane ${ }^{1,2}$, Saïd Boujraf ${ }^{2,3}$, Ismail Rammouz ${ }^{1,2}$

${ }^{1}$ Department of Psychiatry, University Hospital of Fez, ${ }^{2}$ Clinical Neurosciences Laboratory, Faculty of Medicine of Fez, ${ }^{3}$ Department of Biophysics and Clinical MRI Methods, Faculty of Medicine of Fez, Fez, Morocco

Address for correspondence: Dr. Boujraf Saïd, Department of Biophysics and Clinical MRI Methods, Faculty of Medicine and Pharmacy of Fez, BP 1893, Km 2.200, Sidi Hrazem Road, Fez 30000, Morocco. E-mail: sboujraf@gmail.com

\section{REFERENCES}

1. Janssen HL, Brouwer JT, van der Mast RC, Schalm SW. Suicide associated with alfa-interferon therapy for chronic viral hepatitis. J Hepatol 1994;21:241-3.

2. Rifflet H, Vuillemin E, Oberti F, Duverger P, Lainé P, Garré JB, et al. Suicidal impulses in patients with chronic viral hepatitis $\mathrm{C}$ during or after therapy with interferon alpha. Gastroenterol Clin Biol 1998;22:353-7.

3. Quarantini LC, Cruz SC, Batista-Neves SC, Paraná R, 
Miranda-Scippa A, Bressan RA, et al. Psychosis during peginterferon-Alpha 2a and ribavirin therapy: Case report. Braz J Infect Dis 2006;10:406-7.

4. Morasco BJ, Rifai MA, Loftis JM, Indest DW, Moles JK, Hauser $\mathrm{P}$, et al. A randomized trial of paroxetine to prevent interferon-alpha-induced depression in patients with hepatitis $\mathrm{C}$. J Affect Disord 2007;103:83-90.

5. Schaefer M, Hinzpeter A, Mohmand A, Janssen G, Pich M, Schwaiger M, et al. Hepatitis C treatment in "difficult-to-treat" psychiatric patients with pegylated interferon-alpha and ribavirin: Response and psychiatric side effects. Hepatology 2007;46:991-8.

6. Raison CL, Woolwine BJ, Demetrashvili MF, Borisov AS, Weinreib R, Staab JP, et al. Paroxetine for prevention of depressive symptoms induced by interferon-alpha and ribavirin for hepatitis C. Aliment Pharmacol Ther 2007;25:1163-74.

7. Kelly EM, Corace K, Emery J, Cooper CL. Bipolar patients can safely and successfully receive interferon-based hepatitis $\mathrm{C}$ antiviral treatment. Eur J Gastroenterol Hepatol 2012;24:811-6.
This is an open access article distributed under the terms of the Creative Commons Attribution-NonCommercial-ShareAlike 3.0 License, which allows others to remix, tweak, and build upon the work non-commercially, as long as the author is credited and the new creations are licensed under the identical terms.

\begin{tabular}{|l|l|}
\hline \multicolumn{2}{|c|}{ Access this article online } \\
\hline Quick Response Code: & Website: \\
\hline
\end{tabular}

How to cite this article: Aarab C, Aalouane R, Saïd B, Rammouz I. Delicate situation of bipolar disorder and interferon therapy. J Neurosci Rural Pract 2018;9:164-6.

(C) 2018 Journal of Neurosciences in Rural Practice | Published by Wolters Kluwer - Medknow 